\title{
Efeito da Restrição Alimentar Qualitativa Precoce sobre o Desempenho, as Características do Trato Gastrintestinal e a Carcaça de Frangos de Corte ${ }^{1}$
}

\author{
Flavio Alves Longo ${ }^{2}$, Nilva Kazue Sakomura ${ }^{3}$, Mônica Reis Bittencourt Benatti ${ }^{2}$, Otto Mack \\ Junqueira $^{3}$, Irineo Zanella ${ }^{2}$
}

\begin{abstract}
RESUMO - O objetivo deste trabalho foi avaliar os efeitos da restrição alimentar qualitativa precoce sobre o desempenho, as características do trato gastrintestinal e a carcaça de frangos de corte. Um total de 975 pintos de corte de um dia da linhagem "Ross", 15 parcelas com 30 machos cada e 15 parcelas com 35 fêmeas, foi distribuído em delineamento experimental inteiramente casualizado, em esquema fatorial 5 x 2 (forma de restrição x sexo), com três repetições por tratamento. As formas de restrição estudadas foram: 1 - testemunha, sem diluição; 2 -diluição com 15\% de calcário; 3 - diluição com 30\% de calcário; 4 - diluição com 15\% de casca de arroz; e 5 - diluição com $30 \%$ de casca de arroz. Os frangos foram alimentados ad libitum com ração padrão, no período de 1 a 7 dias e de 15 a 45 dias de idade. A restrição alimentar por diluição das rações, conforme cada tratamento, foi aplicada do 8 o ao 140 o dia de idade. Para o período de restrição alimentar, foram formuladas rações com níveis normais de minerais e vitaminas, reduzindo-se os outros nutrientes, conforme a diluição. Os frangos submetidos à restrição alimentar qualitativa precoce, pela diluição com $15 \%$ de calcário e, 15 ou $30 \%$ de casca de arroz, apresentaram ganho compensatório, com bom desempenho final. Entretanto, a restrição com $30 \%$ de calcário foi muito severa, prejudicando o desempenho. Houve alteração nas características do trato gastrintestinal com a restrição alimentar, porém houve recuperação até o momento do abate. Os frangos submetidos à restrição alimentar qualitativa precoce apresentaram menor deposição de gordura e maior deposição de proteína na carcaça em comparação ao controle.
\end{abstract}

Palavras-chave: carcaça, desempenho, frango de corte, restrição alimentar, trato gastrintestinal

\section{Effects of Early-Life Feed Qualitative Restriction on Performance, Characteristics of Gastrintestinal Tract and Carcass of Broilers}

\footnotetext{
ABSTRACT - The objective of this work was to evaluate the effects of the early-life qualitative feed restriction on the performance, gastrintestinal tract characteristics and carcass of broilers. A total of 975 one-d-old "Ross" broiler chicks, 15 plots with 30 males each and 15 plots with 35 females each, was allotted to a completely randomized design in a 5 x 2 (restriction forms x sex) factorial arrangement, with three replicates per treatment. The treatments were: 1- no dilution (control); 2 - dilution with $15 \%$ of limestone; 3 - dilution with $30 \%$ of limestone; 4 - dilution with $15 \%$ of rice hulls; 5 - dilution with $30 \%$ of rice hulls. The broilers were full fed a standard diet from 1 to 7 days and from 15 to 45 days of age. The feed restriction by dilution of diets, according to each treatment, was applied from 8 th to $14^{\text {th }}$ days of age. The diluted were formulated with normal levels of minerals and vitamins, and the other nutrients were reduced according to the dilution. The broilers allotted to early-life qualitative feed restriction, by the dilution with and $15 \%$ of limestone and 15.0 or $30.0 \%$ of rice hulls showed a compensatory growth with a good final performance. However, the restriction with $30 \%$ of limestone was severe, prejudicing the broiler performance. The gastrintestinal tract characteristics alteration occurred with the feed restriction, but there was a recovering up to the slaughter time. The broilers allotted to a qualitative feed restriction showed less fat and more protein deposition in carcass, as compared with the control.

Key Words: carcass, performance, broiler, feed restriction, gastrintestinal tract

\section{Introdução}

Em conseqüência da seleção genética do frango de corte "moderno", responsável pela melhoria no desempenho, têm-se, hoje, animais de crescimento muito acelerado. Entretanto, este aumento no crescimento é também acompanhado por uma série de problemas, como ascite, morte súbita e acúmulo de

gordura, que acabam refletindo em prejuízos para a indústria avícola. Uma técnica de manejo para controlar estes problemas seria limitar a ingestão de alimento pelo animal, ou seja, aplicar a restrição alimentar. O uso de programas de restrição alimentar é apontado por diversos autores (OSBOURN e WILSON, 1960; AUCKLAND e MORRIS, 1971; PLAVINIK e HURWITZ, 1991; JONES e

1 Trabalho apresentado pelo $1 \underline{0}$ autor à Faculdade de Ciencias Agrárias e Veterinárias/UNESP - Campus de Jaboticabal para graduação em Zootecnia.

2 Aluno de Pós-Graduação em Produção Animal - FCAV/UNESP - Departamento de Zootecnia - 14870-000 - Jaboticabal, SP.

3 Professor do Departamento de Zootecnia da FCAV/UNESP- Departamento de Zootecnia - 14870-000 - Jaboticabal, SP.
} 
FARRELL, 1992a,b; e LEESON et al., 1995) como manejo para diminuir o rápido crescimento inicial e, portanto, seus problemas. A restrição alimentar diminui o crescimento das aves no período da limitação da ingestão do alimento, o que, entretanto, pode ser compensado durante o período de realimentação. $\mathrm{O}$ aumento na taxa de crescimento, seguido de período de crescimento retardado, tem sido definido como ganho compensatório (YU et al., 1990). Segundo KESSLER (1994), possível melhora na qualidade da carcaça também pode ser obtida com o uso da restrição alimentar, devido à menor deposição de gordura e maior deposição de tecido magro.

Os problemas decorrentes da alta taxa de crescimento inicial são evidentes, particularmente, em frangos alimentados ad libitum (JONES e FARRELL, 1992a), sendo que este sistema de alimentação é associado por diversos autores a alterações esqueléticas e cardiovasculares e ao fato de proporcionar aumento na hiperplasia e hipertrofia de adipócitos (LEESON e SUMMERS, 1980; CARTWRIGHT, 1991; e JONES E FARREL, 1992b).

Alguns autores (OSBOURN e WILSON, 1960; AUCKLAND e MORRIS, 1971) demonstraram a ocorrência de crescimento compensatório em frangos e perus submetidos à restrição alimentar no início da vida, sem comprometimento do peso corporal à idade de abate. YU et al. (1990) e JONES e FARREL (1992b) relataram o sucesso da restrição alimentar, quando, durante a aplicação desse manejo, as aves restritas perderam gordura e ganharam proteína, resultando em carcaça de melhor qualidade.

Observações de PLAVINIK e HURWITZ (1985) indicam que o ganho compensatório ocorre somente após curto período de restrição alimentar. Intervalos longos, sem quantidade suficiente de nutrientes, podem resultar em atraso de crescimento ou provocar danos permanentes que prejudicam a recuperação do peso (PLAVINIK et al., 1986).

Alguns estudos relatam que os programas de restrição alimentar para frangos de corte não promoveram crescimento compensatório até a idade de abate (YU et al., 1990; ROBINSON et al., 1992; e ZUBAIR e LEESON, 1996). A grande variabilidade nos resultados referentes à ocorrência de crescimento compensatório, em trabalhos envolvendo programas de restrição alimentar, é atribuída aos inúmeros fatores que influenciam a resposta dos frangos ao tempo de restrição na fase inicial da vida. De acordo com OSBOURN e WILSON (1960) e YU e ROBINSON (1992), esses fatores incluem a natureza, a severidade e a duração da restrição, bem como sexo, idade da ave ao início da restrição e grau e padrão da realimentação.

Entre os diversos métodos de restrição alimentar adotados como forma de retardar o crescimento inicial de frangos, destacam-se os da restrição alimentar qualitativa (LEESON et al., 1991). A diluição de dietas é comumente feita por intermédio da utilização de alimentos fibrosos e/ou de baixa digestibilidade, como casca de arroz, calcário, casca de aveia e celulose, ou ainda material inerte como areia. A idéia de se promover restrição qualitativa e não-quantitativa é justamente para se evitarem problemas por falta de alimento como canibalismo, desuniformidade do lote e comprometimento dos órgãos internos das aves. JONES e FARRELL (1992a) também observaram que a utilização de dietas diluídas com $65 \%$ de casca de arroz não comprometeu o desempenho das aves, uma vez que, até 48 dias de idade, o crescimento compensatório permitiu que as aves restritas atingissem o peso do grupo controle.

$\mathrm{Na}$ aplicação do manejo de restrição alimentar, deve-se estabelecer um período suficiente para causar os efeitos da restrição, sem que haja o comprometimento do desenvolvimento da ave. FIGUEIREDO et al. (1995) constataram que o intervalo entre término da restrição e abate influenciou o desempenho, de forma que os programas feitos em idades mais tardias determinaram maior consumo de ração e pior conversão alimentar. Segundo PLAVINIK et al. (1986), quando se aplica a restrição alimentar precoce menos severa, provocando pouca ou nenhuma perda de peso da ave, ocorre melhora na conversão alimentar. Porém, a restrição alimentar severa pode promover melhora na eficiência alimentar, mas existe o risco de não se ter ganho compensatório.

ZUBAIR e LEESON (1994b) observaram que aves submetidas à restrição apresentaram, durante o período de realimentação, aumento na ingestão de alimento, quando comparadas às aves não submetidas à restrição. $\mathrm{O}$ aumento na ingestão de alimento foi relacionado, ainda, ao aumento relativo do trato gastrintestinal, principalmente do papo, proventrículo, pâncreas e fígado, dando, assim, suporte ao crescimento.

De acordo com SCOTT et al. (1991), o trato gastrintestinal tem a função de dar suporte ao crescimento. Assim, limitações na disponibilidade de energia para o crescimento do trato gastrintestinal podem prejudicar o crescimento do animal. Portanto, a manutenção do crescimento do trato digestivo pode ter grande contribuição para que as aves tenham ganho compensatório por intermédio de aumento na eficiência dos processos digestivos. 


\section{Rev. bras. zootec.}

O sucesso da restrição alimentar no início da vida, como meio de reduzir a gordura corporal, está relacionado ao fato de que esta prática promove atraso temporário na deposição de gordura, o qual parece ser restrito a determinado período. De acordo com os resultados de JONES e FARRELL (1992b), até 49 dias de idade, observou-se redução na deposição de gordura em aves submetidas à restrição alimentar, enquanto aos 70 dias de idade este efeito não foi constatado. Constata-se, então, que, apesar do atraso na hiperplasia de adipócitos, não ocorreram alterações em relação ao número total de células em idade mais avançada.

A utilização da restrição alimentar nas primeiras semanas de vida do frango de corte, como forma de reduzir a taxa inicial de crescimento de frangos de corte e, conseqüentemente, reduzir a mortalidade decorrente de doenças metabólicas, promovendo melhor composição de carcaça, reflexo de uma menor adiposidade, apresenta resultados bastante conflitantes. Entretanto, deve-se considerar a variação nas condições em que os programas de restrição alimentar são impostos.

Dentro desse contexto, o objetivo deste trabalho foi avaliar os efeitos da restrição alimentar qualitativa precoce (do 8으 ao 14을 de idade), utilizando dois diferentes tipos de diluentes (casca de arroz e calcário) e dois níveis de inclusão (15 e 30\%) na ração, sobre o desempenho de frangos de corte, bem como sobre as características de carcaça e do trato gastrintestinal.

\section{Material e Métodos}

Este trabalho foi realizado no aviário experimental do Departamento de Zootecnia da Faculdade de Ciências Agrárias e Veterinárias - UNESP - Campus de Jaboticabal. Foram utilizados 975 pintos de corte de 1 dia de idade da linhagem "Ross", sendo 450 machos e 525 fêmeas.

O delineamento experimental utilizado foi o inteiramente casualizado, em esquema fatorial $5 \times 2$ (cinco tipos de manejo alimentar e dois sexos), com três repetições por tratamento, sendo cada unidade experimental composta por 30 machos ou 35 fêmeas. Foram utilizados cinco manejos alimentares: 1- ração testemunha - sem diluição; 2- diluição da ração com 15\% de calcário; 3- diluição com 30\% de calcário; 4- diluição com $15 \%$ de casca de arroz; e 5- diluição com $30 \%$ de casca de arroz.

Os frangos foram alimentados à vontade até o 7으 dia e, após o 15ํ dia de idade, com rações sem
Tabela 1 - Composição percentual e calculada das rações padrões

Table 1 - Percentual and calculated composition of standarts diets

\begin{tabular}{|c|c|c|c|}
\hline \multirow{3}{*}{$\begin{array}{l}\text { Ingrediente (\%) } \\
\text { Ingredient }\end{array}$} & \multirow{2}{*}{\multicolumn{3}{|c|}{$\begin{array}{l}\text { Fase (dias) } \\
\text { Phase (dias) }\end{array}$}} \\
\hline & & & \\
\hline & $1-21$ & $22-37$ & $38-45$ \\
\hline Milho & 53,70 & 58,67 & 64,21 \\
\hline Corn & & & \\
\hline Farelo de soja & 38,23 & 32,92 & 27,50 \\
\hline Soybean meal & & & \\
\hline $\begin{array}{l}\text { Óleo de soja } \\
\text { Soybean oil }\end{array}$ & 3,90 & 4,48 & 4,31 \\
\hline $\begin{array}{l}\text { Fosfato bicálcico } \\
\text { Dicalcium phosphate }\end{array}$ & 2,13 & 1,87 & 1,90 \\
\hline $\begin{array}{l}\text { Calcário } \\
\text { Limestone }\end{array}$ & 1,00 & 1,07 & 1,10 \\
\hline $\begin{array}{l}\text { Sal } \\
\text { Salt }\end{array}$ & 0,40 & 0,40 & 0,40 \\
\hline $\begin{array}{l}\text { Supl.Min. + Vit. }{ }^{1} \\
\text { Mineral and vitamin } \\
\text { premix }^{1}\end{array}$ & 0,50 & 0,50 & 0,50 \\
\hline $\begin{array}{l}\text { DL - Metionina - 99\% } \\
\text { Dl-methionine }\end{array}$ & 0,14 & 0,09 & 0,08 \\
\hline
\end{tabular}

Composição calculada

Calculated composition

\begin{tabular}{|c|c|c|c|}
\hline Proteína bruta (\%) & 22,00 & 20,00 & 18,00 \\
\hline Crude protein & & & \\
\hline Energia met. (kcal/kg) & 3050 & 3150 & 3200 \\
\hline $\begin{array}{l}\text { Met. energy } \\
\text { Extrato etéreo (\%) }\end{array}$ & 5,96 & 6,67 & 6,63 \\
\hline Ether extract & & & \\
\hline $\mathrm{Ca}(\%)$ & 1,00 & 0,95 & 0,95 \\
\hline P disponível (\%) & 0,48 & 0,43 & 0,43 \\
\hline Available $P$ & & & \\
\hline Lisina $(\%)$ & 1,22 & 1,07 & 0,93 \\
\hline Lysine & & & \\
\hline Metionina (\%) & 0,48 & 0,40 & 0,37 \\
\hline $\begin{array}{l}\text { Methionine } \\
\text { Metionina + } \\
\text { Cistina (\%) }\end{array}$ & 0,84 & 0,73 & 0,67 \\
\hline $\begin{array}{l}\text { Met. + Cist. } \\
\text { Fibra bruta }(\%)\end{array}$ & 3,42 & 3,17 & 2,91 \\
\hline
\end{tabular}

${ }^{1}$ Suplemento mineral (por quilograma do produto) Mineral premix (per kilogram of product): ferro (iron), $35.000 \mathrm{mg}$; cobre (copper), $50.000 \mathrm{mg}$; manganês (manganese), $35.000 \mathrm{mg}$; zinco (zinc), $30.000 \mathrm{mg}$; iodo (iodine), $600 \mathrm{mg}$; selênio (selenium), $90 \mathrm{mg}$. Suplemento vitamínico (por quilograma do produto) Vitamin premix (per kilogram of product) - 1 a 21 dias (from 1 to 21 days): vit. A, 2.650.000 UI; vit. $\mathrm{D}_{3}, 500.000 \mathrm{UI}$; vit. E, $2400 \mathrm{mg}$; vit, $\mathrm{K}_{3}, 400 \mathrm{mg}$; vit. $B_{1}, 200 \mathrm{mg}$; vit. $B_{2}, 2000 \mathrm{mg}$; vit. $B_{12}, 3500 \mathrm{mcg}$; ácido pantotênico (pantothenic acid), $2200 \mathrm{mg}$; ácido nicotínico (nicotinic acid), 8500 mg; piridoxina (pyridoxine), $400 \mathrm{mg}$; ácido fólico (folic acid), $200 \mathrm{mg}$; biotina (biotin), $20 \mathrm{mg}$; metionina (methionine), $300 \mathrm{~g}$; colina (choline), $150 \mathrm{~g}$; bacitracina de zinco (zinc bacitracin), $110 \mathrm{~g}$; BHT, 20 g. - 22 a 37 dias (from 22 to 37 days): vit, A, 2.300.000 UI; vit. $\mathrm{D}_{3}, 400.000 \mathrm{Ul}$; vit. E, $1800 \mathrm{mg}$; vit. $\mathrm{K}_{3}, 300 \mathrm{mg}$; vit. $\mathrm{B}_{1}, 150 \mathrm{mg}$; vit. $B_{2}, 1400 \mathrm{mg}$; vit. $B_{12}, 3500 \mathrm{mcg}$; ácido pantotênico (pantothenic acid), 2000 mg; ácido nicotínico (nicotinic acid), 7000 mg; piridoxina (pyridoxine), $250 \mathrm{mg}$; ácido fólico (folic acid), $150 \mathrm{mg}$; biotina (biotin), $20 \mathrm{mg}$; metionina (methionine), $275 \mathrm{~g}$; colina (choline), $125 \mathrm{~g}$; bacitracina de zinco (zinc bacitracin), $125 \mathrm{~g}$; BHT, $20 \mathrm{~g}$. - 38 a 45 dias (from 38 to 45 days): vit. A, 2.500.000 UI; vit. $\mathrm{D}_{3}, 520.000 \mathrm{UI}$; vit. E, $3200 \mathrm{mg}$; vit. $\mathrm{K}_{3}, 320 \mathrm{mg}$; vit. $\mathrm{B} 1,100 \mathrm{mg}$; vit. $\mathrm{B}_{2}, 800 \mathrm{mg}$; vit. $\mathrm{B}_{12}, 4000 \mathrm{mcg}$; ácido pantotênico (pantothenic acid), $1300 \mathrm{mg}$; ácido nicotínico (nicotinic acid), $5000 \mathrm{mg}$; metionina (methionine), $200 \mathrm{~g}$; colina (choline), 140g; BHT, $20 \mathrm{~g}$. 
Tabela 2 - Composição percentual e calculada das rações diluídas para o período de restrição alimentar Table 2 - Percentage and calculated composition of diluted diets for the feed restriction

\begin{tabular}{|c|c|c|c|c|}
\hline $\begin{array}{l}\text { Ingrediente (\%) } \\
\text { Ingredient }\end{array}$ & $\begin{array}{c}15 \% \text { de casca de arroz } \\
15 \% \text { of Rice hulls }\end{array}$ & $\begin{array}{c}30 \% \text { de casca de arroz } \\
30 \% \text { of rice hulls }\end{array}$ & $\begin{array}{l}15 \% \text { de calcário } \\
15 \% \text { of limestone }\end{array}$ & $\begin{array}{l}30 \% \text { de calcário } \\
30 \% \text { of limestone }\end{array}$ \\
\hline Milho & 55,75 & 39,30 & 55,80 & 39,30 \\
\hline Corn & & & & \\
\hline $\begin{array}{l}\text { Farelo de soja } \\
\text { Soybean meal }\end{array}$ & 25,00 & 26,40 & 25,00 & 26,40 \\
\hline $\begin{array}{l}\text { Fosfato bicálcico } \\
\text { Dicalcium phosphate }\end{array}$ & 2,25 & 2,30 & 2,25 & 2,30 \\
\hline $\begin{array}{l}\text { Calcário } \\
\text { Limestone }\end{array}$ & 1,00 & 1,00 & 15,00 & 30,00 \\
\hline $\begin{array}{l}\text { Casca de arroz } \\
\text { Rice hulls }\end{array}$ & 15,00 & 30,00 & - & - \\
\hline $\begin{array}{l}\text { Sal } \\
\text { Salt }\end{array}$ & 0,40 & 0,40 & 0,40 & 0,40 \\
\hline $\begin{array}{l}\text { Supl.Min. + Vit. }{ }^{1} \\
\text { Min. and vitamine premix }{ }^{1}\end{array}$ & 0,50 & 0,50 & 0,50 & 0,50 \\
\hline $\begin{array}{l}\text { DL-Metionina-99\% } \\
\text { Dl-methionine }\end{array}$ & 0,10 & 0,10 & 0,10 & 0,10 \\
\hline $\begin{array}{l}\text { Areia } \\
\text { Sand }\end{array}$ & - & - & 1,00 & 1,00 \\
\hline & \multicolumn{4}{|c|}{$\begin{array}{l}\text { Composição calculada } \\
\text { Calculated composition }\end{array}$} \\
\hline $\begin{array}{l}\text { Proteína bruta }(\%) \\
\text { Crude protein }\end{array}$ & 16,65 & 16,34 & 16,21 & 15,44 \\
\hline $\begin{array}{l}\text { Energia Met. }(\mathrm{kcal} / \mathrm{kg}) \\
\text { Met. energy }\end{array}$ & 2530 & 2040 & 2480 & 1950 \\
\hline $\begin{array}{l}\text { Extrato etéreo (\%) } \\
\text { Ether extract }\end{array}$ & 2,13 & 1,71 & 2,03 & 1,50 \\
\hline $\begin{array}{l}\mathrm{Ca}(\%) \\
\mathrm{P} \text { disponível (\%) }\end{array}$ & $\begin{array}{l}1,14 \\
0,51\end{array}$ & $\begin{array}{l}1,29 \\
0,51\end{array}$ & $\begin{array}{l}6,33 \\
0,51\end{array}$ & $\begin{array}{c}12,04 \\
0,51\end{array}$ \\
\hline $\begin{array}{l}\text { Available P } \\
\text { Lisina }(\%) \\
\text { Lysine }\end{array}$ & 0,85 & 0,85 & 0,85 & 0,85 \\
\hline $\begin{array}{l}\text { Metionina }(\%) \\
\text { Methionine }\end{array}$ & 0,38 & 0,36 & 0,38 & 0,36 \\
\hline $\begin{array}{l}\text { Metionina + Cistina }(\%) \\
\text { Met. + Cist. }\end{array}$ & 0,63 & 0,59 & 0,63 & 0,59 \\
\hline $\begin{array}{l}\text { Fibra bruta }(\%) \\
\text { Crude fiber }\end{array}$ & 8,56 & 14,30 & 2,62 & 2,42 \\
\hline
\end{tabular}

\footnotetext{
${ }^{1}$ Suplemento mineral (por quilograma do produto) Mineral premix (per kilogram of product): ferro (iron), $35.000 \mathrm{mg}$; cobre (copper), $50.000 \mathrm{mg}$; manganês (manganese), 35.000 mg; zinco (zinc), 30.000 mg; iodo (iodine), 600 mg; selênio (selenium), 90 mg. Suplemento vitamínico (por quilograma do produto) Vitamin premix (per kilogram of product) vit. A, $2.650 .000 \mathrm{UI}$; vit. $\mathrm{D}_{3}, 500.000 \mathrm{UI}$; vit. E, $2400 \mathrm{mg}$; vit, $\mathrm{K}_{3}$, $400 \mathrm{mg}$; vit. $\mathrm{B}_{1}, 200 \mathrm{mg}$; vit. $\mathrm{B}_{2}, 2000 \mathrm{mg}$; vit. $\mathrm{B}_{12}, 3500 \mathrm{mcg}$; ácido pantotênico (pantothenic acid) , 2200 mg; ácido nicotínico (nicotinic acid), 8500 mg; piridoxina (pyridoxine), $400 \mathrm{mg}$; ácido fólico (folic acid), $200 \mathrm{mg}$; biotina (biotin), $20 \mathrm{mg}$; metionina (methionine), $300 \mathrm{~g}$; colina (choline), 150 $\mathrm{g}$; bacitracina de zinco (zinc bacitracin), $110 \mathrm{~g}$; BHT, $20 \mathrm{~g}$.
} 
1314 Rev. bras. zootec.

diluente, formuladas para atender às exigências nutricionais das aves em cada fase de criação (Tabela 1). No período de 8 a 14 dias de idade, as aves receberam rações diluídas conforme os tratamentos, as quais foram formuladas com níveis normais de minerais e vitaminas, sendo que os demais nutrientes foram reduzidos conforme o nível da diluição utilizada para cada tratamento (Tabela 2).

Foram avaliados ganho de peso, consumo de ração e conversão alimentar nos períodos de restrição alimentar (8 a 14 dias), realimentação (15 a 45 dias) e período total experimental ( 8 a 45 dias). Foram computados os dados de mortalidade das aves no período total experimental ( 8 a 45 dias), para o cálculo da viabilidade de criação (\% de aves vivas). Aos 14 e 45 dias de idade, foram observados os pesos relativos (\%PV) do trato gastrintestinal (região compreendida entre o papo e o final do reto) do intestino (região compreendida entre o início do intestino delgado e o final do reto) e da moela (sem gordura aderida). Aos 45 dias de idade, foram também observadas as características de carcaça (rendimento de carcaça e o acúmulo de gordura abdominal) e composição da carcaça (proteína e extrato etéreo). Os dados coletados foram analisados pelo programa estatístico ESTAT, desenvolvido pelo Departamento de Ciências Exatas da FCAVJ, e as médias obtidas foram comparadas pelo Teste Tukey.

\section{Resultados e Discussão}

De acordo com os resultados de consumo de ração apresentados na Tabela 3, no período em que foi aplicada a restrição alimentar (8 a 14 dias), observou-se maior consumo de ração para as aves que sofreram restrição com diluição de casca de

Tabela 3 - Médias para o desempenho das aves nos períodos de restrição (8 a 14 dias), realimentação (15 a 45 dias) e total (8 a 45 dias)

Table 3 - Means, for performance of broilers to the food restriction period (8 to 14 days) feeding period (15 to 45 days) and total period (8 to 45 days)

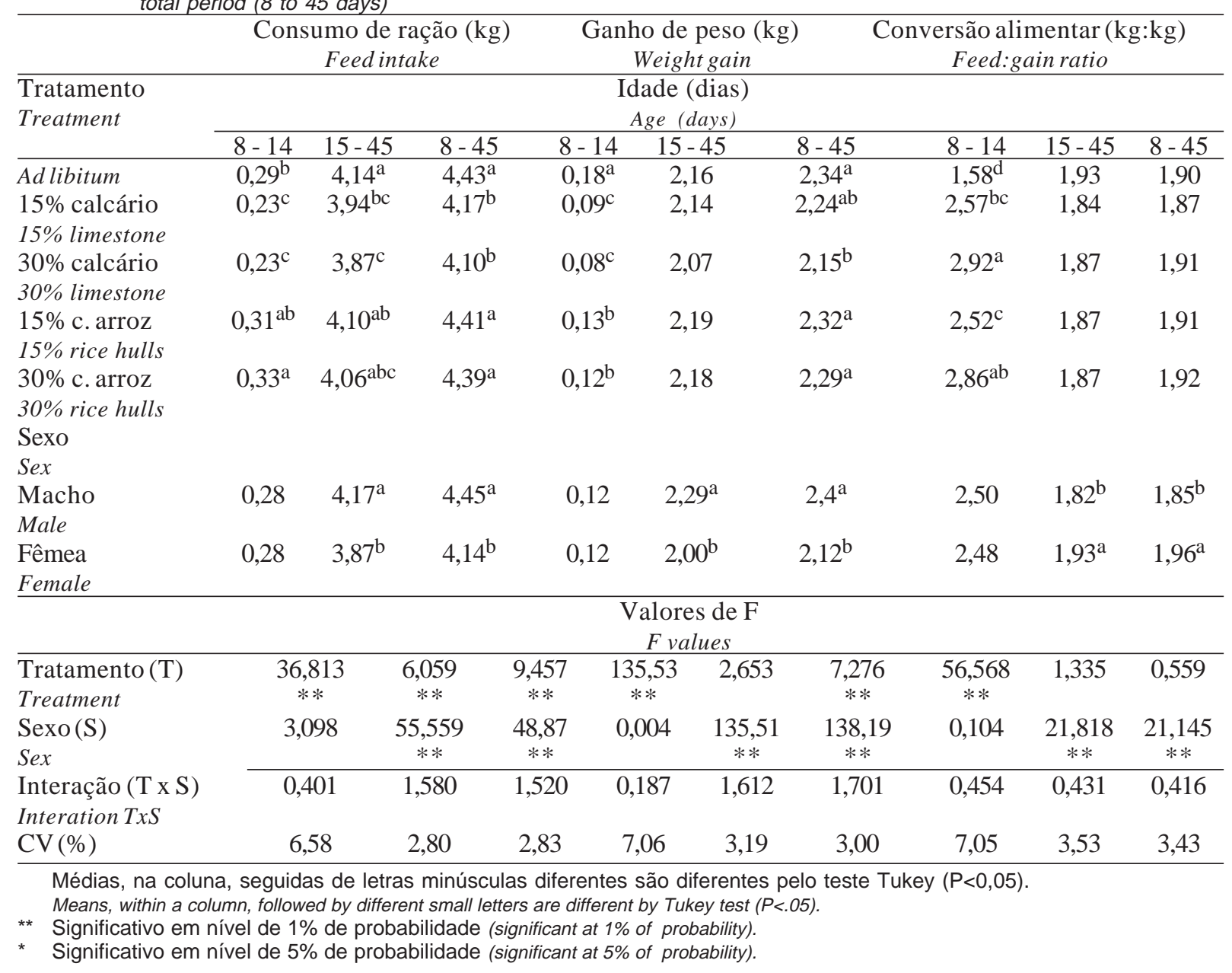


LONGO et al.

Tabela 4 - Médias para as características do trato digestivo das aves aos 14 e 45 dias de idade Table 4 - Means for characteristics of gastrintestinal tract of broilers at 14 and 45 days of age

\begin{tabular}{|c|c|c|c|c|c|c|}
\hline \multirow{3}{*}{$\begin{array}{l}\text { Tratamento } \\
\text { Treatment }\end{array}$} & \multicolumn{2}{|c|}{$\begin{array}{l}\text { Peso do trato (\%PV) } \\
\text { Tract weight }(\% L W)\end{array}$} & \multicolumn{2}{|c|}{$\begin{array}{l}\text { Peso do intestino (\%PV) } \\
\text { Intestinal weight }(\% L W)\end{array}$} & \multicolumn{2}{|c|}{$\begin{array}{l}\text { Peso da moela (\%PV) } \\
\text { Gizzard weight ( } \% L W)\end{array}$} \\
\hline & \multicolumn{6}{|c|}{$\begin{array}{l}\text { Dias de idade } \\
\text { Days of age }\end{array}$} \\
\hline & 14 & 45 & 14 & 45 & 14 & 45 \\
\hline Ad libitum & $14,65^{\mathrm{b}}$ & 6,91 & $7,85^{\mathrm{b}}$ & 3,27 & $4,85^{\mathrm{c}}$ & 3,03 \\
\hline $15 \%$ calcário & $15,8^{\mathrm{ab}}$ & 7,24 & $8,9^{\mathrm{ab}}$ & 3,60 & $4,82^{\mathrm{c}}$ & 2,90 \\
\hline $15 \%$ limestone & & & & & & \\
\hline $\begin{array}{l}30 \% \text { calcário } \\
30 \% \text { limestone }\end{array}$ & $16,29^{a b}$ & 7,16 & $9,39^{a b}$ & 3,43 & $4,69^{\mathrm{c}}$ & 3,19 \\
\hline $\begin{array}{l}15 \% \text { c. arroz } \\
15 \% \text { rice hulls }\end{array}$ & $17,62^{\mathrm{a}}$ & 7,26 & $9,59^{\mathrm{a}}$ & 3,42 & $5,60^{\mathrm{b}}$ & 3,28 \\
\hline $\begin{array}{l}30 \% \text { c. arroz } \\
30 \% \text { rice hulls } \\
\text { Sexo }\end{array}$ & $18,28^{\mathrm{a}}$ & 7,09 & $9,32^{\mathrm{ab}}$ & 3,46 & $6,92^{\mathrm{a}}$ & 3,04 \\
\hline Sex & & & & & & \\
\hline $\begin{array}{l}\text { Macho } \\
\text { Male }\end{array}$ & 16,51 & 6,94 & 9,00 & 3,30 & 5,34 & 3,04 \\
\hline $\begin{array}{l}\text { Fêmea } \\
\text { Female }\end{array}$ & 16,56 & 7,33 & 9,02 & 3,57 & 5,42 & 3,14 \\
\hline & & & $\begin{array}{l}\text { Valores } \\
\text { Fvalue }\end{array}$ & & & \\
\hline $\begin{array}{l}\text { Tratamento(T) } \\
\text { Treatment }\end{array}$ & $5,728 * *$ & $0,352 \mathrm{~ns}$ & $2,943 *$ & $0,444 \mathrm{~ns}$ & $28,123 * *$ & $0,717 \mathrm{~ns}$ \\
\hline $\begin{array}{l}\operatorname{Sexo}(\mathrm{S}) \\
\operatorname{Sex}\end{array}$ & 0,009 & 1,666 & 0,002 & 1,737 & 0,258 & 0,540 \\
\hline $\begin{array}{l}\text { Interação }(\mathrm{T} \times \mathrm{S}) \\
\text { Interaction }(T x S)\end{array}$ & 1,053 & 0,398 & 0,926 & 0,647 & 1,462 & 0,730 \\
\hline $\mathrm{CV}(\%)$ & 8,94 & 12,02 & 11,01 & 16,71 & 8,02 & 13,10 \\
\hline
\end{tabular}

arroz, o qual foi superior ao das aves alimentadas $a d$ libitum; contudo, somente o nível de $30 \%$ de casca de arroz foi significativamente superior $(\mathrm{P}<0,05)$. Este comportamento no consumo de ração também foi observado por LEESON et al. (1991), os quais relataram aumento no consumo de ração, durante o período de restrição, com uma dieta diluída, a fim de se manter a ingestão de nutrientes necessários. Por outro lado, as aves que sofreram restrição com o calcário apresentaram consumo de ração significativamente menor em relação ao das aves dos demais tratamentos. Trabalhos de YU et al. (1990) e PLAVINIK e HURWITZ (1991) também relataram diminuição no consumo de ração, quando aplicado o manejo de restrição alimentar qualitativa. A diversidade nos resultados de consumo de ração, durante o período de restrição, parece estar relacionada ao tipo de diluente utilizado. No período de realimentação (15 a 45 dias), observou-se que as aves dos tratamentos com restrição pela diluição com calcário apresentaram consumo de ração significativamente inferior ao das aves do tratamento ad libitum, indicando efeito depressivo dos altos níveis de cálcio na ração sobre a ingestão. Para o período total do experimento ( 8 a 45 dias), verificou-se consumo significativamente inferior para os tratamentos com diluição pelo calcário.

Houve diferenças significativas de consumo entre os sexos no período de realimentação (15 a 45 dias) e período total ( 8 a 45 dias), sendo que os machos tiveram maior consumo que fêmeas.

Para os valores de ganho de peso, apresentados na Tabela 3, observaram-se diferenças significativas no período em que foi aplicada a restrição alimentar (8 a 14 dias); o ganho das aves submetidas aos tratamentos de restrição com diluição de calcário foi inferior ao das aves tratadas com diluição com casca de arroz, e ambos foram inferiores às aves alimentadas ad libitum. Estes resultados indicam que o calcário 
1316 Rev. bras. zootec.

Tabela 5 - Médias para a viabilidade de 8 a 45 dias e características da carcaça das aves aos 45 dias de idade Table 5 - Means for viability for 8 to 45 days and characteristics of carcass of broilers at 45 days of age

\begin{tabular}{|c|c|c|c|c|c|c|c|}
\hline $\begin{array}{l}\text { Tratamento } \\
\text { Treatment }\end{array}$ & $\begin{array}{c}\text { Viabilidade }(\%) \\
\text { Viability }\end{array}$ & $\begin{array}{c}\text { Rendimento de } \\
\text { carcaça (\%) } \\
\text { Carcass:body } \\
\text { weight ratio (\%) }\end{array}$ & $\begin{array}{c}\text { Gordura } \\
\text { abdominal } \\
(\% \mathrm{PV}) \\
\text { Abdominalfat } \\
(\% \mathrm{BW})\end{array}$ & $\begin{array}{r}\text { Proteína b } \\
\text { Crude prot }\end{array}$ & $\begin{array}{l}n(\% \mathrm{MS}) \\
n(\% D M)\end{array}$ & $\begin{array}{l}\text { Extrato eté } \\
\text { Ether extrc }\end{array}$ & $\begin{array}{l}\text { o }(\% \mathrm{MS}) \\
(\% D M)\end{array}$ \\
\hline & & & & $\begin{array}{l}\text { Macho } \\
\text { Male }\end{array}$ & $\begin{array}{l}\text { Fêmea } \\
\text { Female }\end{array}$ & $\begin{array}{l}\text { Macho } \\
\text { Male }\end{array}$ & $\begin{array}{l}\text { Fêmea } \\
\text { Female }\end{array}$ \\
\hline Ad libitum & 91,20 & 73,58 & 3,05 & $39,67^{\mathrm{b}}$ & $38,94^{\mathrm{b}}$ & $53,05^{\mathrm{aA}}$ & $47,28^{\mathrm{B}}$ \\
\hline $15 \%$ calcário & 89,30 & 72,30 & 2,79 & $44,7^{\mathrm{aA}}$ & $39,19^{\mathrm{bB}}$ & $40,98^{\mathrm{b}}$ & 45,29 \\
\hline $15 \%$ limestone & & & & & & & \\
\hline 30\% calcário & 89,77 & 73,63 & 2,89 & $44,2^{\mathrm{aA}}$ & $40,50^{\mathrm{abB}}$ & $41,99^{b}$ & 46,81 \\
\hline $30 \%$ limestone & & & & & & & \\
\hline $15 \%$ c. arroz & 89,60 & 73,12 & 3,03 & $43,7^{\mathrm{aA}}$ & $41,48^{\mathrm{abB}}$ & $41,39^{b}$ & 42,85 \\
\hline $15 \%$ rice hulls & & & & & & & \\
\hline $30 \%$ c. arroz & 90,57 & 73,52 & 2,93 & $44,35^{\mathrm{a}}$ & $42,4^{\mathrm{a}}$ & $41,66^{b}$ & 44,06 \\
\hline $30 \%$ rice hulls & & & & & & & \\
\hline Sexo & & & & & & & \\
\hline Sex & & & & & & & \\
\hline Macho & $89,11^{\mathrm{b}}$ & 73,36 & 2,72 & & $35^{\mathrm{a}}$ & & \\
\hline Male & & & & & & & \\
\hline Fêmea & $91,06^{\mathrm{a}}$ & 73,09 & 3,15 & & $50^{\mathrm{b}}$ & & \\
\hline Female & & & & & & & \\
\hline & & & $\begin{array}{c}\text { Valores de } \mathrm{F} \\
F \text { values }\end{array}$ & & & & \\
\hline Tratamento(T) & 0,563 & 1,056 & 0,105 & & $75 * *$ & & $9 * *$ \\
\hline Treatment & & & & & & & \\
\hline $\operatorname{Sexo}(\mathrm{S})$ & $4,390 *$ & 0,320 & 2,140 & 35 & $49 * *$ & & 50 \\
\hline Sex & & & & & & & \\
\hline Interação(TxS) & 1,914 & 0,483 & 0,327 & & $04 *$ & & $13 *$ \\
\hline Interaction TxS & & & & & & & \\
\hline $\mathrm{CV}(\%)$ & 2,82 & 2,56 & 27,29 & & 44 & & 25 \\
\hline
\end{tabular}

Médias na linha seguidas de letras maiúsculas diferentes diferem estatisticamente entre si $(P<0,05)$ (Means within a rowfollowed by different capital letters are diferent $(P<.05)$.

Médias na coluna seguidas de letras minúsculas diferentes são diferentes pelo teste Tukey $(P<0,05)($ Means within a column followed by different smal letters are different by Tukey test $(P<.05)$ ).

** Significativo em nível de $1 \%$ de probabilidade (significant at $1 \%$ of probability).

* Significativo em nível de $5 \%$ de probabilidade (significant at $5 \%$ of probability).

promoveu restrição com efeito mais severo que a casca de arroz. Entretanto, no período de realimentação (15 a 45 dias), não foram observadas diferenças significativas entre os tratamentos. FURLAN (1996) observou efeito significativo do nível de restrição sobre o ganho de peso, porém não verificou diferenças entre frangos alimentados ad libitum e restritos em $30 \%$ da quantidade de ração. No período total do experimento ( 8 a 45 dias) observou-se apenas ganho de peso total significativamente inferior para o tratamento de restrição pela diluição com $30 \%$ de calcário.

Tem-se constatado, na literatura, variados resultados quanto à habilidade dos frangos de corte submetidos a período de restrição em promover o ganho compensatório, recuperando ou até mesmo superando o peso de aves alimentadas à vontade, a qual pode estar relacionada à severidade, ao tipo e à duração da restrição alimentar (YU e ROBINSON, 1992).
Quanto aos resultados de conversão alimentar relacionados na Tabela 3 , durante o período em que foi aplicada a restrição alimentar (8 a 14 dias), verificou-se que os níveis de diluição aplicados foram responsáveis pela piora na conversão alimentar das aves. Os tratamentos com níveis de 30\% (calcário e casca de arroz) promoveram pior aproveitamento do alimento, seguidos de aves restritas com diluição de $15 \%$ (calcário e casca de arroz). As aves dos tratamentos de diluição com casca de arroz tiveram pior conversão alimentar, devido ao maior consumo de ração, enquanto, para as aves do tratamento de diluição com calcário, explica-se a piora na conversão alimentar pelo baixo ganho de peso. As aves alimentadas ad libitum apresentaram boa conversão alimentar para a fase, diferindo significativamente das aves restritas. PALO et al. (1995) também observaram pior conversão alimentar no período em 
que foi aplicada a restrição para as aves dos tratamentos que sofreram restrição.

Por outro lado, não houve diferenças na conversão alimentar entre os tratamentos no período de realimentação (15 a 45 dias) e período total do experimento ( 8 a 45 dias). $O$ fato de a diluição de $30 \%$ com calcário não ter proporcionado recuperação no ganho de peso ocorreu em função da falta de recuperação no consumo de ração, proporcionando conversão alimentar semelhante à dos demais tratamentos. Estes dados confirmam os resultados apresentados por Jones e Farrel (1992), citados por PALO et al. (1995), os quais também não observaram diferenças significativas na conversão alimentar, aos 49 dias de idade, de frangos que sofreram restrição e frangos alimentados à vontade.

Entre sexos, foram observadas diferenças significativas no período de realimentação ( 15 a 45 dias), visto que a conversão alimentar das fêmeas foi pior que a dos machos.

Os resultados obtidos para as características do trato gastrintestinal das aves aos 14 e 45 dias de idade, apresentados na Tabela 4, revelam aumento no peso do trato gastrintestinal e intestino das aves que sofreram restrição alimentar em relação às aves alimentadas ad libitum, sendo que as aves dos tratamentos por diluição com casca de arroz apresentaram peso do trato gastrintestinal significativamente maior que as aves do tratamento ad libitum, enquanto as aves submetidas aos tratamentos de diluição com calcário tiveram comportamento intermediário, não diferindo dos demais tratamentos.

Para o intestino observou-se que apenas o tratamento de restrição com diluição de $15 \%$ de casca de arroz ocasionou peso significativamente superior em relação ao tratamento ad libitum.

Maior peso da moela foi observado nas aves do tratamento de restrição por diluição com 30 e $15 \%$ de casca de arroz, diferindo significativamente das aves dos demais tratamentos. Estes resultados são explicados pelo fato de as aves terem consumido mais a ração diluída com casca de arroz e, também, pelo alto teor de fibra, o que, provavelmente, contribuiu para manter o consumo na fase de realimentação. Os resultados obtidos estão de acordo com os resultados apresentados por POKNIAK e CORNEJO (1982), quando o aumento de ingestão dos alimentos de aves restritas foi acompanhado pelo aumento do trato digestivo. FURLAN (1996) também propõe que o aumento do peso da moela seja, provavelmente, resposta ao aumento de ingestão do alimento.
Por outro lado, os pesos de trato, intestino e moela aos 45 dias de idade não foram influenciados significativamente pelos tratamentos, indicando recuperação ou ajuste das características dos segmentos do trato gastrintestinal durante o período de realimentação.

Constam da Tabela 5 os resultados de viabilidade criatória no período total do experimento e as características da carcaça avaliadas aos 45 dias de idade. Pode-se verificar que não se verificaram diferenças significativas para a viabilidade, em função dos tratamentos, mostrando que as diferentes restrições aplicadas não comprometeram as aves; entretanto, para sexo, verificou-se maior viabilidade para as fêmeas.

$O$ rendimento de carcaça ao final do experimento (45 dias) não sofreu diferenças significativas, em função dos tratamentos. ZUBAIR e LEESON (1994a), trabalhando com dietas diluídas, também não observaram diferenças para este parâmetro entre aves restritas e não-restritas. Para a gordura abdominal, também não foram observadas diferenças estatísticas, provavelmente devido às grandes variações ocorridas entre as repetições (CV\%). Vários autores (FURLAN, 1996; YU et al., 1990; e PINCHASOV e JENSEN, 1989) também não encontraram diferenças significativas para a gordura abdominal entre aves que sofreram restrição e aves alimentadas ad libitum. Entretanto, PLAVINIK e HURWITZ (1989) relataram redução na quantidade de gordura abdominal, aos 52 dias de idade, em frangos que sofreram restrição alimentar precoce.

Por outro lado, para a gordura depositada na carcaça (extrato etéreo), observou-se menor deposição em frangos submetidos à restrição, diferindo significativamente do tratamento ad libitum. Houve interação significativa entre sexo e tratamentos, sendo que machos alimentados ad libitum acumularam maior quantidade de gordura na carcaça em relação àqueles submetidos à restrição. Entretanto, esta diferença não foi observada para as fêmeas. Estes dados discordam dos resultados obtidos porZUBAIR eLEESON (1996), os quais não observaram diferenças significativas no acúmulo de gordura na carcaça entre aves submetidas à restrição alimentar e alimentadas ad libitum.

Para a deposição de proteína na carcaça, constatou-se que as aves submetidas à restrição tiveram deposição significativamente maior em relação às do tratamento ad libitum, indicando que a redução da gordura da carcaça proporcionou aumento nos teores de proteína. Os machos tiveram maior deposição de proteína na carcaça, quando submetidos à restrição em relação à alimentação ad libitum. Por outro lado, 
1318 Rev. bras. zootec.

para as fêmeas, somente o tratamento de diluição com $30 \%$ de casca de arroz diferiu estatisticamente, apresentando maior deposição de proteína na carcaça em relação ao tratamento ad libitum.

Estes resultados evidenciam que as formas de restrição aplicadas, tanto pela diluição da ração com casca de arroz como de calcário, foram efetivas para a redução da deposição de gordura corporal e o aumento do teor de proteína, indicando maior deposição de carne que gordura na carcaça dos frangos. Entretanto, PALO et al. (1995), restringindo a ingestão de alimentos de 8 a 14 dias de idade, não observaram diferenças entre tratamentos para a porcentagem de proteína depositada na carcaça.

\section{Conclusões}

Os resultados obtidos neste trabalho evidenciaram que os frangos de corte, quando submetidos à restrição alimentar qualitativa precoce, por meio de diluição da dieta com 15 ou $30 \%$ de casca de arroz e $15 \%$ de calcário, tiveram ganho compensatório.

As características do trato gastrintestinal sofreram alterações com a restrição alimentar, entretanto, houve recuperação durante o período de realimentação.

A restrição alimentar promoveu redução na deposição de gordura e aumentou a deposição de proteína na carcaça dos frangos.

Odesempenho produtivo dos frangos foi influenciado pelo tipo e nível de diluente, sendo a diluição com $30 \%$ de calcário muito severa, prejudicando o desempenho final, entretanto, a diluição com $30 \%$ de casca de arroz atingiu os objetivos da restrição, sem o comprometimento da expressão do potencial de crescimento dos frangos.

\section{Referências Bibliográficas}

AUCKLAND, J.N., MORRIS, T.R. 1971. Compensatory growth in turkeys: effect of undernutrition on subsequent protein requirements. Br. Poult. Sci., 12:41-48.

CARTWRIGHT, A.L. 1991. Adipose cellularity in Gallus domesticus: Investigations to control body composition in growing chickens. J. Nutr., 121:1486-1497.

FIGUEIREDO, A.C.S., SOARES, P.R., FONSECA, J.B. et al. Desempenho de frangos de corte submetidos a diferentes programas de restrição alimentar. In: CONFERÊNCIA APINCO DE CIÊNCIA E TECNOLOGIA AVÍCOLAS, 1995, Curitiba. Anais... Campinas: FACTA, 1995. p.225-226.

FURLAN, R.L. Efeito da restrição alimentar sobre o crescimento e composição da carcaça de frangos de corte. Jaboticabal, SP: FCAV, 1996. 102p. Tese (Doutorado em Zootecnia) Faculdade de Ciências Agrárias e Veterinárias/Universidade Estadual Paulista, 1996.

JONES, G.P.D., FARRELL, D.J. 1992a. Early-life food restriction of chicken. I. Method of aplication, amino acid supplementation and the age at wich restriction should commence. Br. Poult. Sci., 33:579-587.

JONES, G.P.D., FARRELL, D.J. 1992b. Early-life food restriction of chicken. II Effect of food restriction on the development of fat tissue. Brit. Poult. Sci., 33:589-601.

KESSLER, A.M. 1994. Alimentação restrita e crescimento. Atualidades Técnico Informativo, 2(3):12-13.

LEESON, S., DIAZ, G., SUMMERS, J.D. 1995. Poultry metabolic disorders and mycotoxins. Guelph: University Books. 352p.

LEESON, S., SUMMERS, J.D. 1980. Production and carcass characteristics of the broiler chicken. Poult. Sci., 59:786-798.

LEESON, S., SUMMERS, J.D., CASTON, L.J. 1991. Diet diluition and compensatory growth in broilers. Poult. Sci., 70:867-873.

OSBOURN, D.F., WILSON, P.N. 1960. Effects of differents patterns of allocation of a restricted quantity of food upon the growth rate. J. Agric. Sci., 54:278-289.

PALO, E.P., SELL, J.L., PIQUER, F.J. et al. 1995. Effect of early nutrient restriction on broiler chickens. 1. Performance and development of the gastrintestinal tract. Poult. Sci., 74(1):88-101.

PLAVINIK, I., HURWITZ, S. 1985. The performance of broiler chicks during and following a severe feed restriction at early age. Poult. Sci., 64:348-355.

PLAVINIK, I., HURWITZ, S. 1989. Effect of dietary protein, energy and feed pelleting on the response of chicks to early feed restriction. Poult. Sci., 68:1118-1125.

PLAVINIK, I., HURWITZ, S. 1991. Response of broiler chickens and turkey poults to food restriction of varied severity during early life. Br. Poult. Sci., 32:343-352.

PLAVINIK, I., McMURTRY, J.P., ROSEBROUGH, R.W. et al. 1986. Effect of early feed restriction in broilers. I- Growth performance and carcass composition. Growth, 50:68-76.

PINCHASOV, Y., JENSEN, L.S. 1989. Comparison of physical and chemical means of feed restriction in broiler chicks. Poult. Sci., 68:61-69.

POKNIAK, J.A., CORNEJO, S.B. 1982. Effects of energy and protein undernutrition on productive performance and carcass, liver and digestive tract composition of broiler males. Nutrit. Rep. Int., 26:319-327.

ROBINSON, F.E., CLASSEN, H.L., HANSON, J.A. et al. 1992. Growth performance, feed efficiency and the incidence of skeletal and metabolic disease in full-fed and feed restricted broiler and roaster chickens. J. Appl. Poult. Res., 1:33-41.

SCOTT, T.A., BOWERS, S., MACKENZIE, C.J. 1991. The influence of sex, dietary fat source and level, diet dilution, and early feed restriction on growth and anatomical changes in gastrintestinal tract of broilers chickens from 6 to 37 days of age. Poult. Sci., 70:107 (Abstracts).

ZUBAIR, A.K., LEESON, S. 1994a. Effect of varying periods of early nutrient restriction on growth compensation and carcass characteristics of male broilers. Poult. Sci., 73:129-136.

ZUBAIR, A.K., LEESON, S. 1994b. Effect of early feed restriction and realimentation on heat production and changes in sizes of digestive organs of male broilers. Poult. Sci., 73:529-538.

ZUBAIR, A.K., LEESON, S. 1996. Changes in body composition and adipocyte cellularity of male broilers subjected to varying degree of early-life feed restriction. Poult. Sci., 75:719-728.

YU, M.W., ROBINSON, F.E. 1992. The application of shortterm feed restriction to broilers chickens production: a review. J. Appl. Poult. Res., 1(1):147-153.

YU, M.W., ROBINSON, F.E., CLANDINI, M.T. et al. 1990. Growth and body composition of broiler chickens in response to different regimes of feed restriction. Poult. Sci., 69:2074-2081.

Recebido em: 06/11/98 Aceito em: 21/05/99 